\title{
AHP ve TOPSIS Yöntemleri ile Bilgi Teknolojileri Projelerinde Scrum-Kanban-Şelale Uygulamaları Karşılaştırması Araştırma Makalesi/Research Article
}

\author{
Zeynep CEYLAN ${ }^{1}$, (D) Samet GÜRSEV ${ }^{2}$ \\ ${ }^{1}$ Samsun Üniversitesi, Mühendislik Fakültesi, Endüstri Mühendisliği, 55420, Samsun, Turkey \\ ${ }^{2}$ Marmara Üniversitesi Mühendislik Fakültesi, Endüstri Mühendisliği, 34722, İstanbul, Turkey \\ zeynep.ceylan@samsun.edu.tr, sametgursev@gmail.com \\ (Geliş/Received:08.01.2020; Kabul/Accepted:26.06.2020) \\ DOI: $10.17671 /$ gazibtd.672234
}

\begin{abstract}
Özet—Bilişim sektörü, içerdiği teknolojilerin etkisiyle çok hızlı değişmekte ve gelişmektedir. Firmaların, bu değişime ayak uydurması rakipleriyle rekabet etmeleri ve müşteri memnuniyetini sağlayabilmeleri için çok önemlidir. Bu nedenle, firmaların faaliyetlerini devam ettirebilmeleri için bilgi teknolojileri altyapısında sorunsuz ve yenilikçi ilerlemesi gerekmektedir. Bu durum, özellikle bankacılık ve finans sektörlerinde faaliyet gösteren firmalar için kritik öneme sahiptir. Rekabetin yoğun olduğu bu sektörlerde sunulan hizmetin çeşidi ve kalitesi kadar kolay erişilebilir olması da önem taşımaktadır. Mobil uygulamalar, internet üzerinden işlem yapabilme imkânı, chatbotlar bu sektörde yer alan firmaların hem müşteri memnuniyeti artırmakta hem de self servis uygulamalar sayesinde operasyonel iş gücü maliyetinden kurtarmaktadır. Bu çalışmada, Türkiye'de bankacılık sektöründe faaliyet gösteren öncü bir firmanın mobil uygulamasının farklı fonksiyonları içerisinde yer alan ve Scrum, Kanban ve Şelale gibi farklı proje yönetim metotları ile çalışan 4 farklı yazılım geliştirme projesinin genel özellikleri ve başarı kriterleri analiz edilmiştir. Bu dört projenin başarılı olması için ihtiyaç duyduğu ana ve alt kriterler uzman görüşlerine göre belirlenmiştir. Literatürde sıklıkla kullanılan çok kriterli karar verme yöntemlerinden AHP metodu ile kriterler için ağırlık katsayısı belirlenmiş ve daha sonra TOPSIS yöntemi ile başarı sıralaması yapılmıştır. Çalışmanın sonucunda, yazılım geliştirme departmanında Scrum ve Kanban gibi çevik proje yönetimi metotlarını uygulayan projelerin tüm kriterler açısından son derece başarılı oldukları görülmüştür.
\end{abstract}

\section{Comparison of Scrum-Kanban-Waterfall Applications in Information Technology Projects using AHP and TOPSIS Methods}

\begin{abstract}
The information sector is changing and developing very rapidly with the effect of the technologies it contains. It is very important for companies to keep up with this change in order to compete with their competitors and provide customer satisfaction. Therefore, in order for companies to continue their activities, they need to progress smoothly and innovatively in information technology infrastructure. This is especially critical for companies operating in the banking and finance sectors. In these sectors where competition is intense, it is important that the type and quality of the service provided is easily accessible. Mobile applications, the ability to make transactions over the internet, chatbotlar increase customer satisfaction of companies in this sector, as well as self-service applications saves the cost of operational labor. In this study, the characteristics and success criteria of 4 different software development projects which use different project management methods such as Scrum, Kanban, and Waterfall and located in the different functions of a mobile application of a leading company in operating in the banking sector in Turkey were analyzed. The main and sub-criteria that these four projects need to be successful are determined according to expert opinions. The weighting coefficient for the criteria was determined by AHP method, which is one of the multi-criteria decision making methods frequently used in the literature, and then success ranking was performed by TOPSIS method. As a result of the study, it is seen that the projects that implement agile project management methods such as Scrum and Kanban in the software development department are highly successful in terms of all criteria.
\end{abstract}

Keywords - AHP, TOPSIS, Waterfall, Kanban, Scrum, agile, project management 


\section{GIRİŞ (INTRODUCTION)}

Günümüzde yapılan her projenin kendine has özellikleri olduğu için uygun proje yönetiminin belirlenmesi çok önemlidir. Çünkü, projenin başarısı doğru proje yönetimi metodunun seçilmesi ve uygulanmasıyla sağlanır. Başarılı proje yönetimi şirketlerin doğru karar alması ve ilerlemesi için kritik önem taşımaktadır. Proje yönetiminde başarı kriteri istenilen zamanda, istenen içerikte ve belirlenen bütçe ile tamamlanması olup, başarısız projelerin bu 3 özellikten herhangi biri veya hepsinde başarız olması olarak kabul edilmektedir. Şelale (Waterfall) modeli, geleneksel yazılım proje yönetimi metotlarından en eski ve temel olanıdır. Bu yöntemde, analiz fazlara bölünür ve bir fazın çıkışı bir sonraki fazın girişi olur. Fazlar bir şelale gibi daha yüksek bir seviyeden daha düşük seviyeye düştüğü için, şelale modeli olarak adlandırılır. Şelale yönetim modeli projenin ihtiyaçlarını detaylı olarak belirler, planlama yapar, uygular ve uygulama boyunca kontrol edip tamamlar. Bu metot içerisinde analiz ve tasarım süreci çok uzun süre almaktadır ek olarak proje ihtiyaçlarındaki değişimlere hızlı cevap verilmesi risk taşımaktadır. Dokümantasyon süreçleri çok detaylı olarak hazırlanmaktadır. Bu yönetim biçiminde analiz-yazılımtest ve devreye alma aşamaları bir önceki aşamanın tamamen tamamlanmasına bağlıdır. Müşteri ilk aşamada istediği kapsam ve özelliklerden vazgeçerse akış en baştan tekrar edilir. Bu yöntemde, yapılan planlama ve tasarım işlem bitene kadar değiştirilmez. Bir faz tamamlandığında diğer faza geçilir geri dönüş yapılamaz. Proje sonunda elde edilen ürün müșteriye teslim edilir. Bu yöntem genellikle, küçük projelerde iyi çalışır ve ihtiyaç değişkenliğinin düşük olduğu durumlarda etkili olmaktadır. Ancak bu yöntemde, müşteri, yazılım geliştirme çalışmalarına çoğunlukla dâhil olmamakta ve bu nedenle süreç içerisinde değişen müşteri gereksinimleri dikkate alınmamaktadır. $\mathrm{Bu}$ durum, müşteri beklentilerinin eksiksiz karşılanmasını zorlaştırmakta, olası hataların geç fark edilmesine ve hataların giderilmesi için harcanan süre ve maliyetinin artmasına neden olabilmektedir [1].

Özellikle 90'lı yıllarda bilişim teknoloji projelerinin başarısız olması yıllar içerisinde geleneksel yönetim yaklaşımlarının çevik proje yönetimlerine doğru değişmesine sebep olmuştur. Çevik proje yönetimi bu işleyişi daha verimli, daha etkili ve ekip çalışmasına dayalı bir yapıya taşır. Ayrıca, proje tamamlanmadan proje çıtılarını görebilmeyi, her adımında test yapabilmeyi, duruma göre hedefleri değiştirebilmeyi ve müşteri gereksinimlerine hızlı cevap verebilmeyi mümkün kılar [2]. Çevik proje yönetim modeli altında birçok proje yönetim metodu vardır. Kanban ve Scrum, çevik yazılım geliştirmede yaygın olarak kullanılan proje yönetim yaklaşımlarıdır. Kanban ve Scrum gibi metotlar tüm dünya genelinde bir standarta kavuşmuştur ve bu konuda dünya çapında geçerli eğitim ve sertifikasyon süreçleri yer almaktadır. Bu sertifikasyon süreçleri ve standart akışlar ülkeler arası takip edilen projeler için de büyük avantajlar sağlamaktadır. Scrum, projenin belirli bir aşaması için ayrılan ve birbirini ara verilmeksizin takip eden artımlı ve yinelemeli iş dizilimlerinden (Sprint) oluşmaktadır. Başka bir deyişle, Scrum içerisindeki tüm aktiviteler Sprint içerisinde gerçekleşmektedir. Scrum ürünü en hızlı, kaliteli, ucuz olarak servis eden proje yönetim algısıdır. Esnek bir yapıdadır, geri bildirim düşüncesine ve ekip çalışmasına dayalıdır [3]. Şeffaflık, denetleme ve uyarlama olmak üzere üç temel prensipten oluşur. $\mathrm{Bu}$ prensipler sayesinde, proje ile ilgili tüm gelişmeler tüm ekip tarafından anında izlenebilir. Ayrıca, projenin işleyişi düzenli olarak kontrol edilir ve uyarlama özelliği ile proje ihtiyaç duyulan tüm değişikliklere kolaylıkla adapte olabilir. Kanban, sürekli gelişim sağlamaya yardımcı olmak için tasarlanmış yalın yöntemdir. İlk başlangıçta mevcut sisteme değişiklik yapılmadan izleme yapılır. İsraf ve bekleme yaratan noktalar tespit edilir ve bu noktalara bir çözüm bulunur. Kanban'da iş akışı her an değişebilir. Mevcut kartlar önceliklendirmeye bağlı olarak yer değiştirebilir, iş listelerine yenileri eklenebilir ya da kaldırılabilir. Ayrıca Kanban, proje sahiplerinin nasıl çalıştıklarını daha iyi anlamaları için geliştirme ekibi ile yakınlaşıp kişiselleşmelerine izin verir. Bu, geliştiricilerin ekip olarak daha iyi çalışmasına ve başladıklarını çok daha hızlı bitirmesine olanak tanır. Böylece, geliştiricilerin projenin tamamını görmesi sağlanır ve tüm projeyi geliştirebilecek zorluklar önceden belirlenir. Şelale modelinden farklı olarak Scrum ve Kanban metotlarında, müşteri ile sık sık bir araya gelme ve ürünü küçük parçalar halinde yapıp müşteri onayı alarak ilerleme durumu yürütülmektedir. Analiz aşaması tamamlandıktan sonra ürünün bitirilmesi hedeflenir ve değişiklik talepleri için tüm akış sıfırdan başlar. Tablo 1'de çalışma kapsamında ele alınan proje yönetimi metotlarının karşılaştırılması detaylı verilmiştir [4].

Literatürde Scrum, Kanban ve Şelale metotlarının özelliklerini ve değerlendirme kriterlerini içeren pek çok akademik çalışma yer almaktadır. Örneğin, Cocco vd. (2011) çalışmasında Şelale yaklaşımı gibi geleneksel bir yazılım geliştirme yöntemine karşı Kanban ve Scrum yöntemlerinin benimsenmesinin dinamik davranıșını analiz etmişlerdir [5]. Korhonen (2013) çalışmasında, Nokia Siemens Networks' un büyük bir yazılım geliştirme projesinde çevik uygulamaların etkisini ele almıştır. Bu çevik dönüşümün etkisini, dönüşüm başlamadan önce yönetimin belirlediği hedeflere ulaşmada ne kadar başarılı olduğunu değerlendirmiştir [6]. Başar vd. (2015) bir bilgi işlem şirketinin kullandığı yazılım geliştirme tekniklerinin detaylı analizini yapmışlardır [1]. Ömürbek vd. (2015) çalışmalarında AHP ve TOPSIS yöntemleri ile bir üniversitenin Bilgi İşlem Daire Başkanlığınca, Kurumsal Proje Yönetimi Yazılım geliştirmede kullanılabilecek programın seçilmesini amaçlamışlardır. AHP yöntemi ile kriterlerin ağırlıkları belirlenmiş, TOPSIS yöntemi ile de Atlasian, HP, IBM ve Microsoft firmalarının araçları değerlendirilmiştir [7]. Sharma ve Bawa (2016) çalışmasında, 6 popüler çevik yazılım geliştirme yöntemleri arasından karar verebilmek için PROMETHEE ve AHP tabanlı yöntem geliştirmişlerdir [8]. Rasnacis ve Berzisa (2017) çalışmasında çevik proje yönetimi metodolojisinin proje ekibine özel olarak uyarlanması ve uygulanması için yeni bir yöntem sunmuşlardır. Önerilen yöntemle takım yapısını ve motivasyonunu analiz etmek ve 
çevik rolleri, eserleri, süreçleri ve uygulamaları uyarlamanın mümkün olduğunu belirtmişlerdir [9]. Stupar vd. (2017) çalışmasında popüler çevik proje yönetimi metotlarından biri olan Scrum yönteminin geliştirilmesi için bulanık mantığa dayalı bir karar destek sistemi önermişlerdir [10]. Lei vd. (2017) çalışmasında Scrum ve Kanban'ın yazılım geliştirme projeleri üzerindeki etkilerinin istatistiksel analizini yapmışlardır. Sonuçlar hem Scrum'ın hem de Kanban'ın başarılı projelerin geliştirilmesini sağladığı ve Kanban yönteminin proje zamanlamasını yönetmek açısından Scrum yönteminden daha iyi olabileceğini göstermiştir [11]. Gencer ve Kayacan (2017) çevik yöntemler ile şelale modelini proje görünürlüğü, proje karmaşıklığg ve takım büyüklüğü gibi 33 farklı faktör açısından incelemiş ve karşılaştırmışlardır. $\mathrm{Bu}$ karşılaştırma ile, 13 durumda çevik yöntemlerin, 11 durumda şelale modelinin ve 9 durumda ise her iki yöntemin avantajlı olduğunu öne sürmüşlerdir [12]. Şen vd. (2018) çalışmalarında tekstil sektöründe faaliyet gösteren bir perakende şirketinin süreç yönetimi yazılımı seçme problemi için AHP ve Bulanık TOPSIS yöntemlerini ele almışlardır. Çalışmalarında süreçleri tek bir sistemde birleştiren bir yazılım seçerek operasyonlarda zaman kaybının azaltılmasını hedeflemişlerdir [13].
Yılmaz (2019) çalışmasında, yazılım geliştiren üç şirketin yazılım geliştirme yöntemlerini durum çalışması yöntemi ile detaylı olarak incelemiş ve her bir şirketin süreç değişim aktivitelerini sistematik bir şekilde detaylandırmıştır [14]. Özlü (2019) çalışmasında, çeşitli sektörlerde faaliyet gösteren ve Scrum yöntemini tercih eden işletmelerin yazılım geliştirme departmanlarında çevik dönüşümüne etki eden faktörleri detaylı incelemiştir [15]. Khan vd. (2019) çalışmalarında bulanık AHP yaklaşımını kullanarak yazılım süreci iyileştirme başarı faktörlerinin önceliklendirmeye dayalı sınıflandırma geliştirmişlerdir [16]. Srivastava vd. (2020) analitik şebeke süreci (ANP) metodunu kullanarak yazılım endüstrisinde kaliteyi etkileyen en iyi çevik başarı faktörlerini karar verme yaklaşımı ile belirlemeye çalışmışlardır [17]. Bhavsar vd. (2020) çalışmasında yazılım proje yönetiminde kullanılan uygulamalar için Scrum, Kanban ve Şelale yöntemlerinden oluşan yeni bir hibrit yöntem (Scrumbanfall) önermişlerdir [18]. Shameem vd. (2020) çalışmalarında küresel yazılım geliştirme ortamında çevik gelişimin ölçeklendirme programlarını olumsuz yönde etkileyen engellerin belirlemek için bulanık AHP yöntemini kullanmışlardır [19].

Tablo 1. Kanban-Scrum-Şelale proje yönetimi yöntemlerinin karşılaştırılması [4]

(Comparison of Kanban-Scrum-Waterfall project management metho

\begin{tabular}{|c|c|c|c|}
\hline Özellik & Kanban & Scrum & Şelale \\
\hline $\begin{array}{l}\text { Roller ve } \\
\text { Sorumluluklar }\end{array}$ & $\begin{array}{l}\text { Takım için önceden } \\
\text { tanımlanmış rol yoktur. Bir } \\
\text { proje yöneticisi olmasına } \\
\text { rağmen, ekipteki herhangi bir } \\
\text { kişi bunaldığında işbirliği } \\
\text { yapmaya ve devreye girmesine } \\
\text { teşvik edilir. }\end{array}$ & $\begin{array}{l}\text { Her ekip üyesinin önceden } \\
\text { belirlenmiş bir rolü vardır. } \\
\text { Ürün sahibi hedefleri } \\
\text { tanımlar, Scrum yöneticisi } \\
\text { zaman çizelgesini belirler ve } \\
\text { ekip üyeleri işi yürütür. }\end{array}$ & $\begin{array}{l}\text { Roller ve sorumluluklar çok } \\
\text { önceden belirlidir kesinlikle } \\
\text { değiştirilemez }\end{array}$ \\
\hline $\begin{array}{l}\text { Son Teslim } \\
\text { Zamanı \& } \\
\text { Çizelgeler }\end{array}$ & $\begin{array}{l}\text { Ürünler gerektiğinde teslim } \\
\text { edilebilir (bitiş tarihleri işletme } \\
\text { tarafından gerektiği şekilde } \\
\text { belirlenir). }\end{array}$ & $\begin{array}{l}\text { Çıktıların belirlenen sürede } \\
\text { tamamlanması ve } \\
\text { incelenmeye hazır olması } \\
\text { gerekir. }\end{array}$ & $\begin{array}{l}\text { Süreçler birbiri ardınca } \\
\text { siralanır. Tamamlanmış bir } \\
\text { süreç tekrar edilemez diğer } \\
\text { sürece geçilir. }\end{array}$ \\
\hline $\begin{array}{l}\text { Yetkilendirme \& } \\
\text { Önceliklendirme }\end{array}$ & $\begin{array}{l}\text { Ekip üyelerinin önceki görevleri } \\
\text { tamamladıktan sonra yalnızca } \\
\text { yeni görevleri "almasını" } \\
\text { sağlayan bir "çekme sistemi" } \\
\text { veya sistematik bir iş akışı } \\
\text { kullanır. }\end{array}$ & $\begin{array}{l}\text { "Çekme sistemi" kullanır, } \\
\text { her yineleme için toplu iş } \\
\text { çekilebilir. }\end{array}$ & $\begin{array}{l}\text { Mevcut görev üzerine plan } \\
\text { yapilır. }\end{array}$ \\
\hline Değişiklikler & $\begin{array}{l}\text { Projenin tamamlanmasından } \\
\text { önce değişikliğe, yinelemelere } \\
\text { ve sürekli iyileştirmeye izin } \\
\text { verilir. }\end{array}$ & $\begin{array}{l}\text { Sprint sırasındaki } \\
\text { değişiklikler kesinlikle } \\
\text { önerilmez. }\end{array}$ & $\begin{array}{l}\text { Ürün e değişiklik kabul } \\
\text { edilmez. Müşteri ürünü tüm } \\
\text { fazlar tamamlandığında } \\
\text { görür ve test eder. }\end{array}$ \\
\hline $\begin{array}{l}\text { Verimlilik } \\
\text { Ölçümü }\end{array}$ & $\begin{array}{l}\text { "Döngü süresi" veya bir } \\
\text { projenin bir parçasinı baştan } \\
\text { sona tamamlamak için geçen } \\
\text { süreyi kullanarak üretimi ölçer. }\end{array}$ & $\begin{array}{l}\text { Sprintler aracılığıyla hızı } \\
\text { kullanarak üretimi ölçer. Her } \\
\text { bir sprint arka arkaya ve / } \\
\text { veya eşzamanlı olarak } \\
\text { düzenlenir, böylece her ek } \\
\text { sprint kendisinden önceki } \\
\text { başarıyı temel alır. }\end{array}$ & $\begin{array}{l}\text { Proje planlama aşamasında } \\
\text { başlangıç ve bitiş tarihi } \\
\text { belirlenir başarı zaman, } \\
\text { kaynak ve maliyet kısıtlarına } \\
\text { göre değerlendirilir. }\end{array}$ \\
\hline $\begin{array}{l}\text { En Iyi } \\
\text { Uygulamalar }\end{array}$ & $\begin{array}{l}\text { Çok çeşitli önceliklere sahip } \\
\text { projeler için en iyi yöntemdir. }\end{array}$ & $\begin{array}{l}\text { Zaman içinde fazla } \\
\text { değişmeyebilecek kararlı } \\
\text { öncelikleri olan projeler için } \\
\text { en iyi yöntemdir. }\end{array}$ & $\begin{array}{l}\text { Kısa süreli, az detaylı işlerde } \\
\text { ve kaynakların kısıtlı olduğu } \\
\text { durumda öncelikli olarak } \\
\text { tercih edilebilir. }\end{array}$ \\
\hline
\end{tabular}


Literatürde yer alan çalışmalarda da görüldüğü üzere, özellikle son yıllarda yazılım geliştiren firmalarda şelale ve benzeri klasik yönetim algılarının yerini çevik proje yönetimi metotlarına bıraktığ 1 ve buna bağlı olarak gerçekleştirilen bu dönüşümün etkinliğinin araştırılması gerektiği konusunu gündeme getirmiştir. Çalışmanın temel amacı uzman görüşleri ve literatür araştırması ile belirlenen kriterlere bağlı olarak en uygun proje yönetim metodunu belirlemektedir. Bu amaçla, çalışma kapsamında yer alan yazılım geliştirme yöntemlerindeki farklılıklar, projelerde edinilen tecrübeler ve bu edinimlerin süreçler üzerindeki etkileri detaylı tartışılmıştır. Araştırma yapılan finans şirketinde proje ekiplerinin mümkün oldukça aynı özellik ve koşullarda olması sağlanmıştır. Proje değerlendirme kriterleri, literatür araştırması ve uzman görüşlerine göre belirlenmiş ve doğrudan proje yönetim metotlarının başarısını ölçmede kullanılmıştır.

Çalışmanın 2. bölümünde, proje yönetimi yöntemlerinin değerlendirilmesinde kullanılacak metotlar detaylı açıklanmıştır. 3. bölümde, söz konusu firma ve projeler hakkında genel bilgi verilmiş ve değerlendirme kriterleri belirlenmiştir. 4. bölümde analiz sonuçları yorumlanmıştır. Son olarak, 5. bölüm çalışmanın sonuçları ve gelecek çalışmalar hakkında bilgi sunmaktadır.

\section{MATERYAL VE METOT (MATERIAL AND METHOD)}

Analitik Hiyerarşi Proses (AHP) yöntemi, nicel ve nitel faktörleri ölçmek için kullanılan çok kriterli karar verme (ÇKKV) yöntemlerinden biridir [20]. Bu yöntem, karar vermeyi etkileyebilecek yargılara ve duygulara dayalı karar vermeyi de kolaylaştırmaktadır [21, 22]. Ancak, AHP yöntemi alternatifleri sıralarken çok sayıda eşleştirilmiş karşılaştırmaya ihtiyaç duyması nedeniyle bir sıralama yöntemi kadar kolay ve hızlı değildir. Bu durumda, İdeal Çözüme Benzerlik ile Tercih Sıralaması Tekniği- Technique for Order Preference by Similarity to Ideal Solution (TOPSIS) yöntemi basitliği, uygulanabilirliği ve farklı kriterlerin olduğu durumlarda yüksek hassasiyeti nedeniyle sıkça tercih edilmektedir [23]. Bu nedenle, bu çalışmada kriter (ölçüt) ağırlıklandırma AHP metodu ile, yazılım geliştirme yöntemi seçimi ve sıralaması TOPSIS yöntemi ile gerçekleştirilmiştir. Şekil 1' de çalışmanın genel yapısı gösterilmektedir.

\subsection{AHP Yöntemi ile Kriterlerin Ăgırlıklarının} Hesaplanmasl (Computation of Weights of Criteria by AHP Method)

AHP yöntemi 1970'li yıllarda Thomas L. Saaty tarafindan geliştirilen ölçme ve karar vermede yaygın kullanılan bir matematiksel modeldir [24]. AHP, en iyi alternatifi seçmek veya bir dizi alternatifi sıralamak için karar vericiye yardımcı olabilecek bir yöntemdir. AHP süreci, karar seçeneklerinin belirlenmesi, kriterlerin değerlendirilmesi, kriterlerin ağırlıklandırılması ve seçeneklerin sıralanmasını içerir $[25,26]$. Bu yöntemin adımları aşağıdaki gibidir [27].

Adım-1: Uzmanların eşleştirilmiş karşılaştırmaları

$$
\begin{aligned}
& D_{k}=\left[\begin{array}{ccc}
b_{11 k} & \cdots & b_{1 n k} \\
\vdots & b_{i j k} & \vdots \\
b_{n 1 k} & \cdots & b_{n n k}
\end{array}\right], \\
& k=1,2,3, \ldots, K, i=1,2, \ldots, n, j=1,2, \ldots, n
\end{aligned}
$$

Denklem (1)' de ifade edilen $K$ toplam uzman sayısını, $D_{k}$ $k$. uzman tarafindan yapılan eşleştirilmiş karşılaştırma matrisini ve $b_{i j k}$ ise $i$. kriterin $k$. uzmanının bakış açısından $j$. alternatif üzerindeki etki derecesini temsil etmektedir.

Adım-2: Uzman görüşlerinin geometrik ortalamasının hesaplanmas 1

$D=\left[\begin{array}{ccc}d_{11} & \cdots & d_{1 n} \\ \vdots & d_{i j} & \vdots \\ d_{n 1} & \cdots & d_{n n}\end{array}\right]$

$d_{i j}=\sqrt[k]{\prod_{k=1}^{K} b_{i j k}=1 / d_{i j}} \quad \forall i, j$

Denklem (2)' de verilen $D$ matrisi uzman görüşlerinin geometrik ortalamasinı belirtir.

Adım-3: Normalizasyon

$$
r_{i j}=\frac{d_{i j}}{\sum_{i=1}^{n} d_{i j}^{2}} \quad \forall i, j
$$

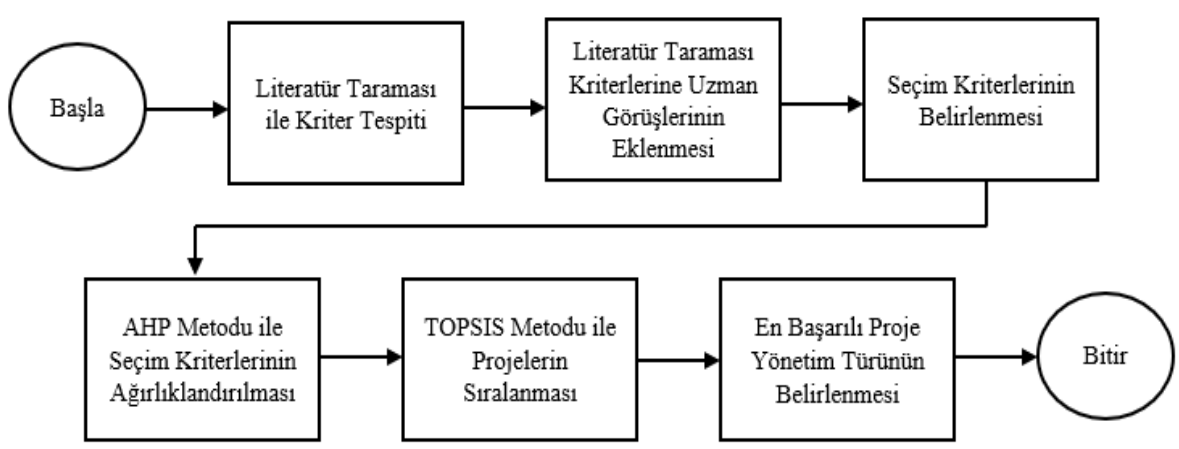

Şekil 1. Çalışmanın genel yapısı (General structure of the study) 
Burada, $r_{i j}$ normalleştirilmiş matris girdilerini belirtir.

Adım-4: Ağırlıkların hesaplanması

$w_{i}=\frac{\sum_{j=1}^{n} r_{i j}}{\sum_{i-1}^{n} \sum_{j=1}^{n} r_{i j}}$

Burada, $w_{i}, i$. kriterin ağırlığını belirtir.

Adım-5: Tutarlık faktörü

$C R=\frac{C I}{R I}$

$C I=\frac{\lambda_{\max }-n}{n-1}$

$\lambda_{\max }=\frac{\sum_{j=1}^{n} d_{i j} w_{j}}{w_{i}}$

Burada, $n$ kriter sayısını, $C R$ ifadesi tutarlık faktörünü, $C I$ tutarlık endeksini, $R I$ ise kararlılık faktörünü gösterir.

\subsection{TOPSIS Yöntemi (TOPSIS Method)}

TOPSIS yöntemi, 1981'de Hwang ve Yoon tarafından geliştirilmiş ÇKKV tekniğidir [28]. Chai vd. (2013) yaptıkları çalışmada, ÇKKV yöntemleri arasında AHP yönteminden sonra eşleştirilmiş karşılaştırmalar gerektirmeyen bir yöntem olan TOPSIS yöntemi \% 63,14 seçim oranı ile en çok tercih edilen yöntem olduğu belirtilmiştir [29]. Ayrıca, farklı pek çok çalışmada, AHP-TOPSIS yönteminin çok iyi performans gösterdiği görülmüştür [30-33].

TOPSIS, çözüm alternatifinin pozitif ideal çözüme olan en k1sa mesafesini ve negatif ideal çözüme olan en uzak mesafesini aynı anda seçen basit ve popüler bir sıralama yöntemidir. $\mathrm{Bu}$ yöntemde $m$ alternatifleri $n$ indisi ile gösterilirse, problem $n$-boyutlu bir uzayda $m$ noktalarından oluşan geometrik bir sistem olarak düşünülebilir. $\mathrm{Bu}$ yöntemin adımları aşağıdaki gibidir [28]:

Adım-1: Karar matrisinin elde edilmesi

$X=\left[\begin{array}{ccc}x_{11} & \cdots & x_{1 n} \\ \vdots & \ddots & \vdots \\ x_{m 1} & \cdots & x_{m n}\end{array}\right]$

Burada, $X$ karar matrisi, $x_{i j}$ ise $i$. alternatifin j. kritere göre elde edilen sayısal değerini göstermektedir. $\mathrm{Bu}$ matriste, pozitif arzu edilebilirlik indeksi ve negatif arzu edilebilirlik indeksi sırasıyla kâr ve maliyet indeksleridir.

Adım-2: Normalizasyon

$V=\left[\begin{array}{ccc}v_{11} & \cdots & v_{1 n} \\ \vdots & \ddots & \vdots \\ v_{m 1} & \cdots & v_{m n}\end{array}\right]$ $v_{i j}=\frac{x_{i j}}{\sqrt{\sum_{i=1}^{i=n} x_{i j}^{2}}} \quad \forall i, j$

Burada, $V$ ve $v_{i j}$ sirasiyla normal matrisi ve normalleştirilmiş matrisin girdilerini gösterir.

Adım-3: Ağırlıklı normalleştirilmiş karar matrisinin oluşturulması

Normalize $V$ matrisi $m \times n$ boyutunda olduğundan, ağırlıklandırma, kriterlerin ağırlıklarını içeren bir $n \times$ $n$ diyagonal matrisi aracılığılla yapılır. Daha sonra ağırlıklı normal matris, normal matrisin diyagonal ağırlık matrisi ile çarpılmasıyla elde edilir:

$W=V \times\left[\begin{array}{ccc}w_{1} & \cdots & 0 \\ \vdots & \ddots & \vdots \\ 0 & \cdots & w_{n}\end{array}\right]=\left[\begin{array}{ccc}w_{11} & \cdots & w_{1 n} \\ \vdots & \ddots & \vdots \\ w_{n 1} & \cdots & w_{n n}\end{array}\right]$

Burada, $W$ ve $w_{i j}$ sirasıyla ağırlıklı normal matrisi ve girdilerini göstermektedir.

Adım-4: Pozitif ve negatif ideal çözümlerinin belirlenmesi

$J=\{j=1,2, \ldots, n\}$

$J^{\prime}=\{j=1,2, \ldots, n\}$

Burada, $J$ ve $J^{\prime}$ sirasiyla kâr ve maliyet indeksi olduğu varsayılırsa, $A^{+}$(pozitif ideal çözüm) ve $A^{-}$(negative ideal çözüm) değerleri denklem (15) ve (16)' daki gibi hesaplanır.

$$
\begin{aligned}
& A^{+}=\left\{\left(\max _{i} w_{i j}, j \in J\right),\left(\min _{i} w_{i j}, j \in J^{\prime}\right)\right\} \quad \forall i \\
& =\left\{a_{1}^{+}, a_{2}^{+}, \ldots, a_{j}^{+}, \ldots, a_{n}^{+}\right\} \\
& A^{-}=\left\{\left(\min _{i} w_{i j}, j \in J\right),\left(\max _{i} w_{i j}, j \in J^{\prime}\right)\right\} \quad \forall i \\
& =\left\{a_{1}^{-}, a_{2}^{-}, \ldots, a_{j}^{-}, \ldots, a_{n}^{-}\right\}
\end{aligned}
$$

Burada, $a_{j}^{+}$ve $a_{j}^{-}$sirasıyla $A^{+}$ve $A^{-}$vektörlerinin girdilerini temsil eder.

Adım-5: Mesafelerin elde edilmesi

Bu adımda, her $n$-boyutlu nokta arasındaki mesafe, Öklid yöntemi kullanılarak pozitif ve negatif ideal çözümlerden elde edilebilir.

$$
\begin{aligned}
& S_{i}^{+}=\sqrt{\sum_{j=1}^{n}\left(w_{i j}-a_{i}^{+}\right)^{2}} i=1,2, \ldots, m \\
& S_{i}^{-}=\sqrt{\sum_{j=1}^{n}\left(w_{i j}-a_{i}^{-}\right)^{2}} i=1,2, \ldots, m
\end{aligned}
$$


Burada, $S_{i}^{+} i$. alternatifin pozitif ideal seçeneğe olan uzaklığını, $S_{i}^{-} i$. alternatifin negatif ideal seçeneğe olan uzaklığını temsil eder.

Adım-6: İdeal çözüme nispi yakınlığın hesaplanması

$C_{i}=\frac{S_{i}^{-}}{S_{i}^{-}+S_{i}^{+}} \quad i=1,2, \ldots, m \quad 0<C_{i}<1$

Burada, $C_{i}, i$. alternatifin ideal çözüme göreli yakınlığıdır. Eğer $i$. alternatif $A^{+1}$ ya eşitse, $C_{i}$ değeri 1'e ve $A^{-1}$ ya eşitse $C_{i}$ değeri 0 ' a eşit olacaktır. Bu, alternatifin, ideal çözüme olan mesafesi ne kadar az olursa, göreli yakınlığın o kadar yüksek olacağı anlamına gelir.

\section{Adım-7: Alternatifleri sıralama}

$\mathrm{Bu}$ adımda, alternatifler ideal çözüme göreli $\left(C_{i}\right)$ değerlerine göre azalan sırada sıralanır ve en büyük değer en iyi seçilir.

\section{UYGULAMA (APPLICATION)}

Bu çalışmada, Türk bankacılık sektöründe yer alan büyük ve kurumsal bir firmanın bilgi teknolojileri (BT) birimindeki Scrum, Kanban, Şelale ve herhangi bir metot uygulamayan 4 farklı yazılım geliștirme projesi incelenmiștir. Şekil 2' de firmanın 2010-2018 yılları arasında benimsediği proje yönetimi yöntemine göre yıllık proje-adet dağılım grafiği gösterilmektedir.

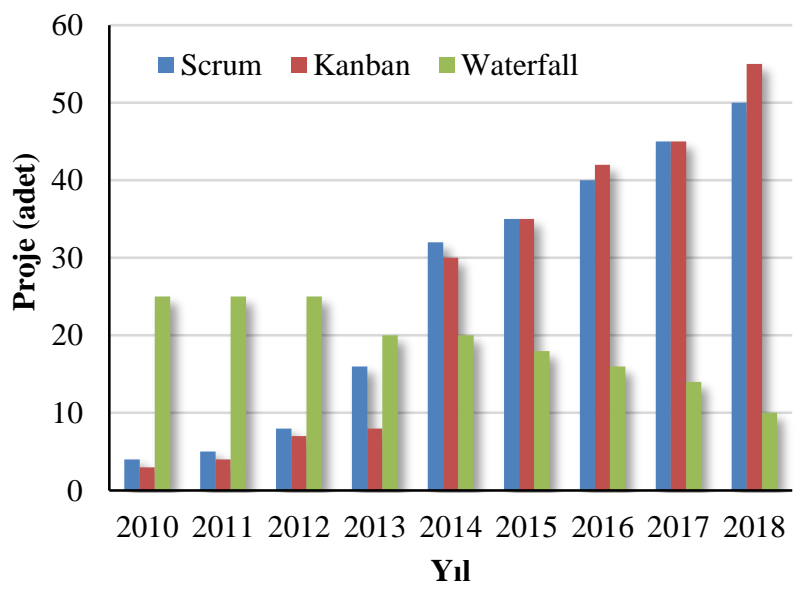

Şekil 2. Yıllık proje sayısı (Annual number of projects)

Şekil 2’ de görüldüğü üzere 2010-2013 yılları arasında firma genelinde şelale proje yönetimi hâkim iken, eş zamanlı olarak çevik proje metotlarından Scrum ve Kanban uygulamaları da ekiplerde uygulanmaya başlanmıştır. Ancak, 2013 yılı sonrasında Şelale modelindeki hakimiyet yerini Scrum ve Kanban metotlarına bırakmaktadır. Şekil 3' de yer alan proje tamamlanma (başarı) oranlarının şelale yaklaşım için ihtiyaçları karşılamadığı ve çevik yaklaşımlara göre daha düşük olduğu görülmektedir. Öte yandan, yıllar içinde projelerin kapsamları, içerikleri ve ekiplerdeki personeller değişmesine rağmen Scrum ve Kanban metotları uygulayan projeler istenen özelliklerde ve belirlenen sürede tamamlanmış, yüksek başarı oranını yıllara göre korumuştur. Ayrıca, benzer teknoloji ve aynı büyüklükteki ekiplerce çözümlenen tüm proje ekiplerinde çevik, yenilikçi ve etkili koordinasyon sağlayan proje yöneticilerinin daha büyük fark yarattığı gözlemlenmiştir. Burada proje yönetim metotlarına ek olarak başarılı liderlik, yüksek motivasyon ve ekip uyumu kriterlerinin de proje performansını etkileyebildiği gözlemlenmiştir.

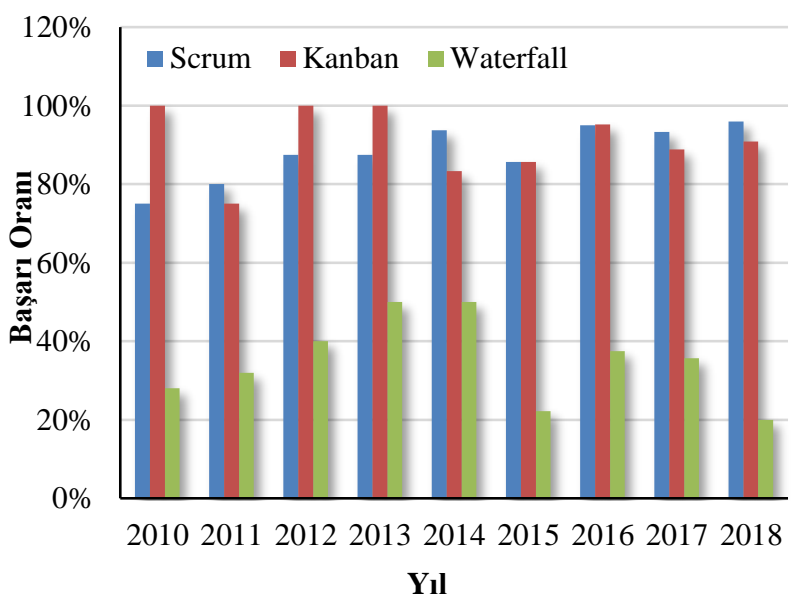

Şekil 3. Yıllara göre projelerin başarı oranı (The success rate of projects by years)

Bu çalışmada, söz konusu firmada 2019 yılında 6 aylık bir süre içerisinde bir mobil uygulamanın farklı fonksiyonları içerisinde gerçekleştirilen ve aynı personel sayısı, aynı bütçe ve içeriğe sahip 4 yazılım geliştirme projesi ele alınmıştır. Projelerde kullanılan proje yönetimi metodu ve içeriği hakkında detaylı bilgiler aşağıda verilmiştir:

- P1: Scrum yöntemi uygulayan takım

- P2: Kanban yöntemi uygulayan takım

- P3: Şelale yöntemi uygulayan takım

- P4: Metot uygulamadan ilerleyen takım

Yukarıda bahsi geçen her proje için 5'er kişilik proje ekipleri oluşturulmuştur. Her projede, geçmişte yaptıkları proje tecrübeleri bakımından benzer deneyimlere ve aynı eğitim seviyesine sahip 1 analist, 1 test uzmanı, 3 yazılımcı ünvanında takım üyeleri yer almaktadır. Scrum master, Kanban master ve proje yöneticisi rolleri sırasıyla P1, P2 ve P3 projesinde analist görevinde olan kişiye ek görev olarak verilmiştir. P4 proje ekibinde ise herhangi bir proje metodu veya proje yöneticisi görevi bulunmamaktadır. P3 ve P4 projeleri arasındaki en önemli fark süreçlerin P4 projesinde daha belirsiz olması, bir proje yöneticisi olmaması, takım üyelerinin projenin başlangıç ve bitiş tarihlerine bağlı kalarak kendi başına hareket etmesidir.

Projelerdeki ekipler firma ile yaptıkları sözleşmelere göre dört farklı proje yönetimi uygulaması ile ilerlemeyi kabul etmişlerdir. Ekiplerin hepsi analiz, yazılım, test ve ürün 
kabul testleri fazlarından oluşan aynı proje planına sahiptir. Projelerin tamamı mobil uygulama üzerinde aynı teknolojide ve yaklaşık 100 adam/gün efor verilmiş işlev değişikliği içermektedir. Takım üyelerinin talep ettikleri donanım ve lisans kurulumları önceden tamamlanmıştır. Dört proje ekibi aynı ay ve aynı günde projeye başlamış ve ekiplerin tamamı kendilerine ait proje odalarında birbirinden bağımsız yerlerde çalışmış ve böylece proje süresi boyunca proje ekipleri arasında herhangi bir etkileşim olmamıştır. P1 ve P2 projeleri sahip oldukları çevik metotları eksiksiz kullanan ve rol ve sorumlulukları belirlenmiş takım üyelerinden oluşmaktadır. P1 ve P2 ekiplerinde her gün düzenli “daily” adı verilen 15 'er dk'lık kısa toplantılar yapılarak takım üyeleri bilgilendirilmiş ve literatüre uygun duyuru panoları ile projenin güncel durumu paylaşılmıştır. Ayrıca, P1 ve P2 ekipleri projeyi küçük fazlara bölmüş ve iki haftada bir yaptıkları plan ve durum değerlendirme toplantıları ile projenin mesai planını ve kaynak yönetimini takip etmişlerdir.

P3 ve P4 ekiplerinde ise bu toplant1lar ve duyuru panoları yer almamaktadır. P3 ekibi analiz ve test fazı bittiğinde bağlı bulunduğu müdürlüğe sunum yapmıştır. P4 ekibi ise tüm proje boyunca etkileşim sağlayacak hiçbir toplantı, sunum vb. etkinlik yapmamıştır. Tamamlanan projeleri değerlendirmek için kullanılacak ana ve alt kriterleri belirlemek üzere araştırma konusunda uzman, akademik çalışmalar yapmış ve uzun yıllar üst düzey yöneticilik yapmış kişilere anket uygulanmıştır. Ayrıca, bu süreçte müşterilerden görüş alınmış, proje esnasında ve bitimde hazırlanan raporlar detaylı olarak incelenmiştir. Literatür araştırması ve uzman görüşleri değerlendirmesi sonrasında 3 ana kriter ve 12 alt kriter yazılım geliştirme projelerinin değerlendirilmesi için büyük önem taşıdığı tespit edilmiş ve Tablo 2' de belirtilmiştir.

Tablo 2. Proje değerlendirmesinde kullanılacak ana ve alt kriterler (The main and sub-criteria to be used in project evaluation)

\begin{tabular}{|c|c|c|c|}
\hline Ana Kriter & Kod & Alt Kriter(ler) & Kod \\
\hline & & Kullanım Kolaylığ & c1 \\
Müşteri & \multirow{2}{*}{ A1 } & Yeterlik & c2 \\
Memnuniyeti & & Güvenirlik & c3 \\
& & Kalite & \\
\hline Kaynakların & & Bütçe & c5 \\
Etkin & \multirow{2}{*}{ A2 } & İşgücü & c6 \\
Kullanımı & & Proje Süresi & c7 \\
& & Verimlilik & c8 \\
\hline & & Adaptasyon Süresi & c9 \\
& & Değişim Entegrasyonu & c10 \\
Esneklik & \multirow{2}{*}{ A3 } & KararAlma Memnuniyeti & c11 \\
& & Kapsam & c12 \\
& & &
\end{tabular}

Yapılan literatür araştırması ve uzman görüşleri doğrultusunda projelerin başarılı olması için müşteri memnuniyetinin sağlanması, kaynakların etkin kullanılması ve değişimlere çabuk cevap verebilen esnek bir yapıda olması ana kriterler olarak belirlenmiştir.
Müşteri memnuniyeti ana kriteri altında yer alan kullanım kolaylığı kriteri, geliştirilen uygulamanın müşteri tarafindan çabuk öğrenilen ve az işlem ile sonuca ulaşmasını sağlayan bir yapıda olmasını içermektedir. Yeterlik alt kriteri, ürünün müşteri tarafından iletilmiş olan tüm ihtiyaç ve isteklerini tam olarak karşılamasını içermektedir. Güvenilirlik kriteri ise iki açıdan üründe önem teşkil etmektedir. İlk olarak bilgi güvenliği ve dış saldırılara karşı sistemin korunaklı olması ikinci olarak da yapılan geliştirme sonrasında program tarafindan gerçekleştirilen tüm fonksiyon ve hesaplamaların doğru yapılması konusunda başarılı olmasını içermektedir. Kalite parametresi de yazılımın istekleri karşılamasına ek olarak performans ve işlem kabiliyetinden uzun süre kayıp vermeden ilerlemesi ve müşteri memnuniyeti odaklı olmasını içermektedir.

Kaynakların etkin kullanımı, proje türü ne olursa olsun ana değerlendirme kriteridir. Yazılım geliştirme projelerinde bu kriter genellikle bütçe, işgücü, proje süresi ve verimlilik olmak üzere dört alt başlıktan oluşmaktadır. Bütçe kriteri aslında sadece proje ekibine yapılan ödeme değil aynı zamanda alınan donanım, bilgisayar ve lisans bedellerini içeren bir kriterdir. İşgücü kriteri, proje planında hesaplanan iş gücünün fazla mesai ve düşük tempo değerlerinden uzak durup normal mesai saatleri içerisinde tüm ekibin etkili ve verimli çalışmasını içermektedir. Başından sonuna fazla mesai içeren projeler aslında yanlış kaynak planlaması göstergesidir. Proje süresi, yazılım geliştirme projelerinde özellikle sözleşme yapıldığ aşamada büyük önem verilen bir kriterdir. Aslında bütçe ve iş gücü kriterlerini de etkilemektedir. Günümüzde pek çok yazılım geliştirme projesi istenen tarihte bitirilmemesi takdirinde cezai işlem uygulamaktadır. Özellikle kanun değişikliği sonrasında yapılan yazılım geliştirmelerinde proje süresine uyulması büyük önem taşımaktadır. Verimlilik de kaynakların etkin kullanımı konusunda önemli bir kriterdir. Sadece personelin değil, dişardan temin edilen tüm kaynakların etkili ve verimli kullanılması önemlidir.

Esneklik ana kriteri ve içerdiği alt kriterlerle birlikte diğer proje tiplerine kıyasla yazılım geliştirme projelerinde büyük rol oynayan önemli bir kriterdir. Yazılım süreçlerinde analiz aşamasında ne kadar detaya girilse bile yazılım geliştirme aşamasında yapılan kod analizi sürecinde ön görülmemiş büyük çaba gerektiren işler meydana gelebilir. Buna ek olarak, müşteri ilk başlangıçta talebi ile ilgili istekleri yeterince detaylı aktaramamış olabilir. Özellikle ekran tasarımlarında müşteri talepleri geliştirme aşamasında sıklıkla değişime uğrayabilir. Tüm bunlara ek olarak yazılım projesi devam ederken diğer projeler ile ortak geliştirme yapılan platformlarda değişiklikler ve revizyonlar meydana gelebilir. Bir yıldan uzun süren yazılım geliştirme projelerinde müşteri taleplerinde veya çevre etkilerde değişiklik olması çok yüksek oranlara sahiptir. Buna bağlı olarak gelen değişime karşı adaptasyon süresinin kısa olması ve ister ile ilgili entegrasyonun yapılabilir olması iki önemli kriterdir. Tüm bu değişikliklerin ekip içerisinde hızlı karar alınarak ilerlenmesi ve ekipçe benimsenmesi de önemli bir 
kriterdir. Kapsam kriteri de proje boyunca hedeflenen ürünün istenen özelliklerde çıkması ve bu özellikleri esneklik dahilinde yapılmış tüm değişiklikleri de içerecek bir şekilde çıkmasını içermektedir.

\section{ANALIZZ SONUÇLARI VE TARTIŞMA (ANALYSIS RESULTS AND DISCUSSION)}

\subsection{AHP Yönteminin Uygulanmasl (Application of AHP Method)}

Yapılan literatür araştırmasında proje yönetimi seçiminde etkili olan en popüler kriterler belirlenmiştir [7-12]. Bu kriterler içerisinden çalışma kapsamında kullanılacak kriterlerin belirlenmesi için Türk bankacılık sektöründe Bilişim Teknolojileri proje yöneticileri, Scrum Master ve Kanban Master unvanları ile çalışan ve alanında uzman üst düzey yöneticilerden oluşan 20 kişilik bir ekibin görüşleri alınmıştır. Yapılan görüşmeler sonucunda proje yönetimi seçimi için her biri 4 alt kriterden oluşan 3 ana kriter (müşteri memnuniyeti, kaynakların etkin kullanımı ve esneklik) belirlenmiştir.

Proje seçiminde kullanılacak kriterler belirlendikten sonra aynı yöneticilere kriter ağırlıklarının belirlenmesi amacıyla anket uygulanmıştır. Anket kapsamında, her bir yönetici kriterlere ilişkin ikili karşılaştırma matrisini doldurmuştur. İkili karşılaştırmalarda 1-9 arasında bir skala kullanılmış ve yöneticilerin bu skalayı temel alarak kriterler arasındaki önem derecesine karar vermeleri sağlanmıştır. Kriterlere ilişkin karşılaştırma işlemlerinde kullanılan önem skalası Tablo 3'de verilmiştir [20].

Tablo 3. Çalışma kapsamında kullanılan ölçek (The scale used in the study)

\begin{tabular}{|c|c|}
\hline $\begin{array}{l}\text { Önem } \\
\text { Değerleri }\end{array}$ & Değer Tanımları \\
\hline 1 & $\begin{array}{l}\text { Her iki faktörün eşit öneme sahip olmas1 } \\
\text { durumu }\end{array}$ \\
\hline 3 & $\begin{array}{l}\text { 1. faktörün 2. faktöre göre biraz daha } \\
\text { önemli olması durumu }\end{array}$ \\
\hline 5 & $\begin{array}{l}\text { 1. faktörün 2. faktörden fazla önemli } \\
\text { olması durumu }\end{array}$ \\
\hline 7 & $\begin{array}{l}\text { 1. faktörün 2. faktöre göre çok fazla } \\
\text { öneme sahip olması durumu }\end{array}$ \\
\hline 9 & $\begin{array}{l}\text { 1. faktörün 2. faktöre göre üstün bir } \\
\text { öneme sahip olması durumu }\end{array}$ \\
\hline $2,4,6,8$ & Ara değerler \\
\hline
\end{tabular}

Projelerin değerlendirilmesinde kullanılacak ana ve alt kriterler belirlendikten sonra her bir yöneticinin ikili karşılaştırma puanlarının geometrik ortalamaları alınıp ortak görüş elde edilmiş ve AHP metodu kullanılarak ilgili kriterlerin ağırlıkları MS Excel paket programında hesaplanmıştır. Yazılım geliştirme projelerinin seçimini etkileyen ana ve alt kriterler, ağırlıkları ve kodları Tablo 4'te verilmiştir. Tutarlılık oranı (CR) ikili karşılaştırma matrisleri için hesaplanır. Bu oran için önerilen üst limit 0,10 'dur [35].
Tablo 4. AHP metodu ile elde edilen kriter ağırlıkları (The criteria weights obtained by AHP method)

\begin{tabular}{|c|c|c|}
\hline $\begin{array}{c}\text { Ana } \\
\text { Kriter }\end{array}$ & Alt Kriter & $\begin{array}{c}\text { Kriter-Önem } \\
\text { Derecesi }\end{array}$ \\
\hline Müşteri & Kullanım Kolaylığı & 0.07 \\
Memnuniyeti & Yeterlik & 0.08 \\
0.25 & Güvenirlik & 0.06 \\
& Kalite & 0.04 \\
\hline Kaynakların & Bütçe & 0.05 \\
Etkin & İşgücü & 0.08 \\
Kullanımı & Proje Süresi & 0.12 \\
0.35 & Verimlilik & 0.10 \\
\hline & Değişisliklik Süresi & 0.14 \\
Esneklik & Değişim Entegrasyonu & 0.08 \\
0.40 & Karar Alma Memnuniyeti & 0.12 \\
& Kapsam & 0.06 \\
\hline
\end{tabular}

CR değerinin 0,10'un altında olması karar vericinin yeterli bir tutarlılık sergilediği ve değerlendirmenin devam edebileceği kabul edilir. Ancak, bu oranının 0,10'un üstünde olması karar vericinin ikili karşılaştırmalarda tutarsız olduğunu gösterir. Bu durumda yargıların yeniden gözden geçirilmesi gerekir. $\mathrm{Bu}$ çalışmada yer alan ikili karşılaştırmalar matrisi için hesaplanan CR değeri 0,09 olarak hesaplanmıştır. Bu oran 0,10'dan küçük olduğu için elde edilen sonuçların tutarlı olduğu sonucuna varılmıştır.

\subsection{TOPSIS Yönteminin Uygulanması (Application of TOPSIS Method)}

TOPSIS yöntemine göre ilk olarak karar matrisi oluşturulmuş ve projelerin her bir kriter açısından değerlendirilmesi sonucunda almış olduğu puanlar 100 üzerinden hesaplanarak Tablo 5 ' te gösterilmiştir. Karar matrisindeki sütunlardaki her bir değerin ilgili sütundaki bütün değerlerin kareleri toplamının kareköküne bölünmesiyle Tablo 6'da görülen normalize edilmiş karar matrisi elde edilir [36]. Tablo 4' te AHP metodu ile elde edilen kriter ağırlıkları TOPSIS yönteminin analizinde kullanılmış ve Tablo 6' da yer alan normalize değerler ile çarpılarak Tablo' 7 de gösterilen ağırlıklı standart karar matrisini oluşturulmuştur. Ağırlıklı karar matrisi hesaplandıktan sonra, TOPSIS yönteminde yer alan pozitif ideal $\left(A^{+}\right)$ve negatif ideal $\left(A^{-}\right)$çözüm setleri Tablo $8^{\prime}$ de gösterildiği gibi oluşturulmuştur.

$\mathrm{Bu}$ değerlerin oluşturulmasında, Tablo 7' de hesaplanan ağırlıklandırılmış karar matrisinin sütunlarında yer alan en büyük değerler pozitif ideal çözüm seti için seçilirken en küçük değerler ise negatif ideal çözüm seti seçilmiştir. Sütunlarda yer alan her bir kritere ait olan değerlerden pozitif ideal ve negatif ideal değerler çıkarılarak karar noktalarının pozitif ideal $\left(S_{i}^{+}\right)$ve negatif ideal $\left(S_{i}^{-}\right)$çözüme olan uzaklıkları hesaplanmıştır. Daha sonra, her alternatif için ideal çözüme olan nispi yakınlık $\left(C_{i}\right)$ hesaplanmıştır. Tablo 9' da bu hesaplamalar ve sonucunda elde edilen siralama gösterilmektedir. 
Tablo 5. Karar matrisi (Decision matrix)

\begin{tabular}{|c|c|c|c|c|c|c|c|c|c|c|l|l|}
\hline Proje Kriter & $\mathrm{c1}$ & $\mathrm{c} 2$ & $\mathrm{c} 3$ & $\mathrm{c} 4$ & $\mathrm{c5}$ & $\mathrm{c6}$ & $\mathrm{c7}$ & $\mathrm{c} 8$ & $\mathrm{c} 9$ & $\mathrm{c} 10$ & $\mathrm{c} 11$ & $\mathrm{c} 12$ \\
\hline P1 & 70 & 75 & 76 & 78 & 65 & 80 & 70 & 80 & 79 & 78 & 78 & 78 \\
\hline P2 & 68 & 66 & 78 & 80 & 64 & 85 & 72 & 82 & 82 & 80 & 80 & 80 \\
\hline P3 & 61 & 51 & 63 & 61 & 60 & 81 & 61 & 62 & 63 & 65 & 64 & 64 \\
\hline P4 & 61 & 41 & 42 & 40 & 50 & 71 & 41 & 32 & 42 & 43 & 78 & 30 \\
\hline
\end{tabular}

Tablo 6. Normalize karar matrisi

(Normalized decision matrix)

\begin{tabular}{|c|c|c|c|c|c|c|c|c|c|c|c|c|}
\hline $\mathrm{Proje}_{\text {Kriter }}$ & $\mathrm{c} 1$ & c2 & c3 & c4 & c5 & c6 & c7 & c8 & c9 & $\mathrm{c} 10$ & c11 & c12 \\
\hline $\mathrm{P} 1$ & 0.537 & 0.628 & 0.573 & 0.585 & 0.541 & 0.504 & 0.563 & 0.596 & 0.578 & 0.573 & 0.518 & 0.590 \\
\hline P2 & 0.522 & 0.553 & 0.588 & 0.600 & 0.533 & 0.535 & 0.579 & 0.611 & 0.600 & 0.587 & 0.531 & 0.605 \\
\hline P3 & 0.468 & 0.427 & 0.475 & 0.457 & 0.500 & 0.510 & 0.490 & 0.462 & 0.461 & 0.477 & 0.425 & 0.484 \\
\hline P4 & 0.468 & 0.343 & 0.317 & 0.300 & 0.416 & 0.447 & 0.329 & 0.239 & 0.307 & 0.316 & 0.518 & 0.227 \\
\hline
\end{tabular}

Tablo 7. Ağırlıklı karar matrisi (Weighted decision matrix)

\begin{tabular}{|c|c|c|c|c|c|c|c|c|c|c|c|c|}
\hline Proje & c1 & c2 & c3 & c4 & c5 & c6 & c7 & c8 & c9 & c10 & c11 & c12 \\
\hline $\mathrm{P} 1$ & 0.038 & 0.050 & 0.034 & 0.023 & 0.027 & 0.040 & 0.068 & 0.060 & 0.081 & 0.046 & 0.062 & 0.035 \\
\hline P2 & 0.037 & 0.044 & 0.035 & 0.024 & 0.027 & 0.043 & 0.069 & 0.061 & 0.084 & 0.047 & 0.064 & 0.036 \\
\hline P3 & 0.033 & 0.034 & 0.028 & 0.018 & 0.025 & 0.041 & 0.059 & 0.046 & 0.065 & 0.038 & 0.051 & 0.029 \\
\hline P4 & 0.033 & 0.027 & 0.019 & 0.012 & 0.021 & 0.036 & 0.040 & 0.024 & 0.043 & 0.025 & 0.062 & 0.014 \\
\hline
\end{tabular}

Tablo 8. Pozitif ve negatif ideal çözüm setleri (Positive and negative ideal solution sets)

\begin{tabular}{|c|c|c|c|c|c|c|c|c|c|c|c|c|}
\cline { 2 - 12 } \multicolumn{1}{c|}{} & $\mathrm{c} 1$ & $\mathrm{c} 2$ & $\mathrm{c} 3$ & $\mathrm{c} 4$ & $\mathrm{c} 5$ & $\mathrm{c} 6$ & $\mathrm{c} 7$ & $\mathrm{c} 8$ & $\mathrm{c} 9$ & $\mathrm{c} 10$ & $\mathrm{c} 11$ & $\mathrm{c} 12$ \\
\hline$A^{+}$ & 0.033 & 0.027 & 0.019 & 0.012 & 0.021 & 0.036 & 0.040 & 0.024 & 0.043 & 0.025 & 0.051 & 0.014 \\
\hline$A^{-}$ & 0.038 & 0.050 & 0.035 & 0.024 & 0.027 & 0.043 & 0.069 & 0.061 & 0.084 & 0.047 & 0.064 & 0.036 \\
\hline
\end{tabular}

AHP yöntemleri ile elde edilen 12 alt kriterin ağırlıkları göz önüne alınarak yapılan analiz sonrasında TOPSIS yöntemi ile P1-P2-P3-P4 şeklinde bir sıralama elde edilmiştir. Sonuçlar, sırasıyla Scrum $(\cong 0.995)$ ve Kanban $(\cong 0.994)$ yöntemlerini uygulayan $\mathrm{P} 1$ ve $\mathrm{P} 2$ proje ekibinin müşteri memnuniyeti, kaynakların etkin kullanımı ve esneklik konusunda son derece başarılı olduğunu göstermiştir. Değerlendirmeye alınan dört proje ekibi için proje başladıktan kısa bir süre sonra müşteri tarafından uygulamalar üzerinde yapılacak bazı değişiklik talepleri gelmiştir. $\mathrm{Bu}$ taleplere Scrum ve Kanban yöntemleri ile çalışan P1 ve P2 proje ekipleri çok hızlı bir şekilde entegre olmuş ve üründe istenen değişiklikleri dahil ederek projeyi istenen zamanda teslim etmiştir. P1 ve P2 proje ekibinin proje süresi boyunca müşteri ile sürekli iletişimde olması, müşteri beklentilerinin tam olarak karşılanmasını ve ürün bittikten sonra kabul sürecinin risksiz olmasını sağlamıştır.
Ayrıca, P1 ve P2 proje ekibinin düzenli olarak yaptığ toplantılar projenin güncel durumunu takip ederek projenin önceliklerini hızlıca değiştirmesini sağlamıştır. Böylece, gecikmeye neden olan sorunlara alternatif çözümler üretilmiş ve hatta müşteri ile tekrar değerlendirme yapılarak ürün üzerinde değişiklikler yapılabilmiştir. Ancak, şelale yöntemi ile uygulamasını devam ettiren P3 proje ekibi analiz aşamasına kadar müşteri ile birlikte çalışmış ve müşterilerin isteklerini çok net olarak analiz etmiştir. Ancak, Bankacılık Düzenleme ve Denetleme Kurumu (BDDK) tarafindan yapılan mevzuat değişiklikleri sonrasında ürün geliştirme sürecinde revizyon ve ek özellik ihtiyacı oluşmuştur. Bu ihtiyaçların karşılanması için şelale yönetim modelinde analiz-yazılımtest akışı tamamlanıp yeni gelen talepler başka bir talep kapsamında alınmış ve incelenmiştir. 
Tablo 9. TOPSIS yöntemine göre siralama (Sorting by TOPSIS method)

\begin{tabular}{|c|c|c|c|}
\cline { 2 - 4 } \multicolumn{1}{c|}{} & $S_{i}^{+}$ & $S_{i}^{-}$ & $C_{i}$ \\
\hline P1 & 0.00549 & 0.00003 & 0.994988 \\
\hline P2 & 0.00590 & 0.00004 & 0.993652 \\
\hline P3 & 0.00196 & 0.00137 & 0.587329 \\
\hline P4 & 0.00013 & 0.01272 & 0.009698 \\
\hline
\end{tabular}

P3 ekibi yazılım ve test aşamasında müşteri ile yeterince sık bir araya gelmemiş ve diğer proje ekiplerine göre bu yeni isteklerin alınması konusunda geç kalmıştır. Müşteri diğer ekiplerden gelen hızlı dönüş ve yönlendirmeler ile süreci istediği seviyeye getirmiştir. Hiçbir proje yönetim metodu kullanmayan P4 proje ekibi ise özellikle kapsam bütçe, işgücü, süre ve verimlilik kriterlerinde beklenen değerin çok altında kalmıştır.

\section{SONUÇ (CONCLUSION)}

Yazılım geliştirme süreçleri, firmaların operasyonel süreçlerden kurtulması, müşteri memnuniyetini sağlaması ve rakipleriyle rekabet edebilmesi için büyük önem taşımaktadır. $\mathrm{Bu}$ nedenle, proje kapsamının doğru belirlenmiş olması, analizinin detaylı ve kapsama uygun hazırlanması, yazılım sürecinin mümkün olan en kısa sürede ve en yeni tekniklerle hazırlanması ve tüm bu sürecin eksiksiz test edilmesi projenin istenen başarıya ulaşmasına yardımcı olmaktadır. $\mathrm{Bu}$ süreçlerin doğru ve etkili yapılabilmesi için iyi bir ekip, başarılı bir planlama, etkili kaynak ve proje yönetimi gerekmektedir.

$\mathrm{Bu}$ çalışmada, Türk bankacılık ve finans sektöründe faaliyet gösteren bir firmanın yazılım proje yönetiminde farklı metotlar kullanan 4 farklı projesinin süreç değișimini izlemek ve projelerin performanslarını ölçmek amaçlanmıştır. Araştırma yapılan birimde her proje ekibinin mümkün oldukça aynı özellik ve koşullarda olması sağlanmıștır. Proje yönetim metotlarının başarısını ölçmek için ana ve alt kriterler uzman görüşleri ve akademik çalışmalar baz alınarak belirlenmiş ve AHP metodu ile ağırlıklandırılmıştır. AHP metodundan elde edilen ağırlıklar ÇKKV yöntemlerinden biri olan TOPSIS yönteminde kullanılarak proje yöntemi metotlarının başarı sıralaması yapılmıştır. Analiz sonuçlarından görüldüğü üzere, söz konusu firmada klasik yönetim metotlarından biri olan şelale modeli ile verim alınmadığı görülmüştür. Bu nedenle, firmanın başarılı proje yönetimi için Scrum ve Kanban gibi çevik metotları kullanmasının daha etkili olacağı sonucuna varılmıştır.

$\mathrm{Bu}$ çalışmanın, bu alanda araştırma yapmak isteyen araştırmacıların kalite metrikleri, test performans ölçümleri ve yazılım ürünlerinin performans kriterleri gibi konularda literatüre katkı sağlayacağı düşünülmektedir. Ayrıca, Endüstri 4.0 kapsamında yazılım süreçlerinin yapay zekâ etkisiyle farklılaşması beklenmektedir. Gelecek çalışmalar için, Endüstri 4.0 uygulamasının proje yönetimi yaklaşımları üzerindeki etkilerinin analizi yeni bir araștırma konusu olabilir.

\section{KAYNAKLAR (REFERENCES)}

[1] A. Başar, A. Özkaya, F. Kesgin, "Yazılım Geliştirme Süreçlerinde Şelale Yönteminden Çevik Yaklaşıma Geçiş: Bir Teknoloji Şirketinde Uygulama”, 9. Ulusal Yazılım Mühendisliği Sempozyumu, İzmir, 9-11 Eylül, 2015.

[2] Çevik Bildirinin Temelindeki İlkeler, https://agilemanifesto.org/iso/tr/manifesto.html, 01.01.2020.

[3] M. Elibol, Ç. Selçukcan Erol, "Scrum Metodu Kullanılarak Bir Mobil Uygulama Geliştirme Sürecinin Gerçekleştirilmesi”, Bilişim Teknolojileri Dergisi. 10(2), 169-176, 2017.

[4] Kanban vs. Scrum: What are the differences, https://leankit.com/learn/kanban/kanban-vs-scrum/,14.12.2019.

[5] L. Cocco, K. Mannaro, G. Concas, M. Marchesi, "Simulating kanban and scrum vs. waterfall with system Dynamics", International Conference on Agile Software Development, Berlin, 117-131, 10-13 May, 2011.

[6] K. Korhonen, "Evaluating the impact of an agile transformation: a longitudinal case study in a distributed context", Software Quality Journal, 21(4), 599-624, 2013.

[7] N. Ömürbek, Y. Makas, V. Ömürbek, "AHP ve TOPSIS Yöntemleri ile Kurumsal Proje Yönetim Yazılımı Seçimi”, Süleyman Demirel Üniversitesi Sosyal Bilimler Enstitüsü Dergisi, (21), 59-83, 2015

[8] A. Sharma, R. K. Bawa, "A framework for agile development method selection using modified PROMETHEE with Analytic Hierarchy Process”, International Journal of Computer Science and Information Security, 14(8), 846, 2016.

[9] A. Rasnacis, S. Berzisa, "Method for adaptation and implementation of agile project management methodology", Procedia Computer Science, 104, 43-50, 2017.

[10] M. Stupar, P. Milošević, B. Petrović, “A fuzzy logic-based system for enhancing scrum method", Management: Journal of Sustainable Business and Management Solutions in Emerging Economies, 22(1), 47-57, 2017.

[11] H. Lei, F. Ganjeizadeh, P.K. Jayachandran, P. Ozcan, “A statistical analysis of the effects of Scrum and Kanban on software development projects", Robotics and Computer-Integrated Manufacturing, 43, 59-67, 2017.

[12] C. Gencer, A. Kayacan, "Yazılım Proje Yönetimi: Şelale Modeli ve Çevik Yöntemlerin Karşılaştırılması”, Bilişim Teknolojileri Dergisi, 10(3), 335-352, 2017.

[13] A. Y. Şen, N. Semiz, B. Güneş, D. Algül, Z. Gergin, N.D. Dönmez, "The Selection of a Process Management Software with Fuzzy Topsis Multiple Criteria Decision Making Method", In The International Symposium for Production Research, 150-167, Springer, Cham., 2018.

[14] M. Yılmaz, "Üç yazılım firmasında yazılım süreç değişimlerinin gözlenen etkileri: Endüstriyel keşif vaka çalışması", Pamukkale Üniversitesi Mühendislik Bilimleri Dergisi, 25(2), 240-246, 2019.

[15] E. Özlü, Yazılım geliştirme süreçlerinde scrum'ı tercih eden işletmelerin çevik dönüşümüne etki eden faktörlerin incelenmesi, Doktora Tezi, İstanbul Medeniyet Üniversitesi, Lisansüstü Eğitim Enstitüsü İşletme Anabilim Dalı, 2019. 
[16] A.A. Khan, M. Shameem, R.R. Kumar, S. Hussain, X. Yan, "Fuzzy AHP based prioritization and taxonomy of software process improvement success factors in global software development", Applied Soft Computing, 83, 105648, 2019.

[17] A. Srivastava, D. Mehrotra, P.K. Kapur, A.G. Aggarwal, "Analytical evaluation of agile success factors influencing quality in software industry", International Journal of System Assurance Engineering and Management, 1-11, 2020.

[18] K. Bhavsar, V. Shah, S. Gopalan, "Scrumbanfall: An Agile Integration of Scrum and Kanban with Waterfall in Software Engineering”, International Journal of Innovative Technology and Exploring Engineering (IJITEE), 9(4), 2075-2084, 2020.

[19] M. Shameem, R.R. Kumar, M. Nadeem, A.A. Khan, "Taxonomical classification of barriers for scaling agile methods in global software development environment using fuzzy analytic hierarchy process", Applied Soft Computing, 90, 106122, 2020.

[20] T.L. Saaty, The Analytic Hierarchy Process, McGraw-Hil International Book Company, USA, 1980.

[21] O. Bayazit, "Use of AHP in decision-making for flexible manufacturing systems", Journal of Manufacturing Technology Management, 16(7), 808-819, 2005.

[22] S. Sindhu, V. Nehra, S. Luthra, "Investigation of feasibility study of solar farms deployment using hybrid AHP-TOPSIS analysis: Case study of India", Renewable and Sustainable Energy Reviews, 73, 496-511, 2017.

[23] M. Pekkaya, "Career preference of university students: an application of MCDM methods", Procedia Economics and Finance, 23, 249-255, 2015.

[24] T.L. Saaty, "A scaling method for priorities in hierarchical structures”, Journal of mathematical psychology, 15(3), 234-281, 1977.

[25] R.P., Singh, H.P. Nachtnebel, "Analytical hierarchy process (AHP) application for reinforcement of hydropower strategy in Nepal", Renewable and Sustainable Energy Reviews, 55, 43-58, 2016.

[26] H. Karahalios, "The application of the AHP-TOPSIS for evaluating ballast water treatment systems by ship operators", Transportation Research Part D: Transport and Environment, 52, 172-184, 2017.
[27] A. Azimifard, S.H. Moosavirad, S. Ariafar, "Selecting sustainable supplier countries for Iran's steel industry at three levels by using AHP and TOPSIS methods", Resources Policy, 57, 30-44, 2018.

[28] C. L. Hwang, A.S.M. Masud, Multiple objective decision making - methods and applications: a state-of-the-art survey, Springer Science \& Business Media, 1979.

[29] J. Chai, J.N. Liu, E.W. Ngai, "Application of decision-making techniques in supplier selection: A systematic review of literature", Expert systems with applications, 40(10), 3872-3885, 2013.

[30] F.R.L. Junior, L. Osiro, L.C.R. Carpinetti, "A comparison between Fuzzy AHP and Fuzzy TOPSIS methods to supplier selection", Applied Soft Computing, 21, 194-209, 2014.

[31] M. C. Lin, C. C. Wang, M. S. Chen, C. A. Chang, "Using AHP and TOPSIS approaches in customer-driven product design process", Computers in Industry, 59(1), 17-31, 2008.

[32] V. Jain, A. K. Sangaiah, S. Sakhuja, N. Thoduka, R. Aggarwal, "Supplier selection using fuzzy AHP and TOPSIS: a case study in the Indian automotive industry", Neural Computing and Applications, 29(7), 555-564, 2018.

[33] S. K. Patil, R. Kant, “A fuzzy AHP-TOPSIS framework for ranking the solutions of Knowledge Management adoption in Supply Chain to overcome its barriers", Expert Systems with Applications, 41(2), 679-693, 2014.

[34] H. H. Asadi, A. Sansoleimani, M. Fatehi, E. J. M. Carranza, “An AHP-TOPSIS predictive model for district-scale mapping of porphyry $\mathrm{Cu}-\mathrm{Au}$ potential: a case study from Salafchegan area (central Iran)", Natural Resources Research, 25(4), 417-429, 2016.

[35] B. Akça, A. Doğan, U. Özcan, "Analitik Hiyerarşi Süreci Kullanılarak Kişi Takip Cihazı Seçimi”, Bilişim Teknolojileri Dergisi, 8(1), 20-35, 2015.

[36] M. Yorulmaz, Y. İç, A. Seyrek, "Bilgisayar Değiştirme Kararları için Bir Karar Destek Sisteminin Geliştirilmesi”, Bilişim Teknolojileri Dergisi, 12(3), 195-202, 2019. 